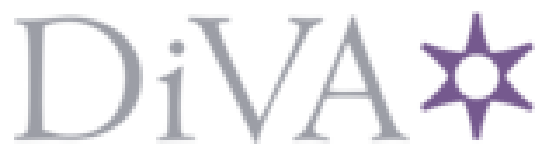

http://www.diva-portal.org

This is the published version of a paper published in Desalination and Water Treatment.

Citation for the original published paper (version of record):

Zhang, W., Blum, K M., Gros, M., Ahrens, L., Jernstedt, H. et al. (2018)

Removal of micropollutants and nutrients in household wastewater using organic and inorganic sorbents

Desalination and Water Treatment, 120: 88-108

https://doi.org/10.5004/dwt.2018.22836

Access to the published version may require subscription.

N.B. When citing this work, cite the original published paper.

Permanent link to this version:

http://urn.kb.se/resolve?urn=urn:nbn:se:umu:diva-152904 


\title{
Removal of micropollutants and nutrients in household wastewater using organic and inorganic sorbents
}

 \\ B. Björlenius ${ }^{\mathrm{d}}$, G. Renman ${ }^{\mathrm{a}}$ \\ ${ }^{a}$ Department of Sustainable Development, Environmental Science and Engineering, KTH Royal Institute of Technology, \\ Teknikringen 10B, SE-10044 Stockholm, Sweden, email: zhangw@kth.se (W. Zhang), gunno@kth.se (G. Renman) \\ ${ }^{b}$ Department of Chemistry, Umeå University, Linnaeus väg 6, SE-90187 Umeå, Sweden, email: kristinblum89@gmail.com (K. Blum), \\ patrik.andersson@umu.se (P.L.Andersson) \\ 'Department of Aquatic Sciences and Assessment, Swedish University of Agricultural Sciences, Box 7050, SE-75007 Uppsala, Sweden, \\ email:mgros@icra.cat (M. Gros), lutz.ahrens@slu.se (L.Ahrens),henrik.jernstedt@slu.se (H. Jernstedt),karin.wiberg@slu.se (K.Wiberg) \\ ${ }^{d}$ Department of Biotechnology, KTH Royal Institute of Technology, AlbaNova University Centre, SE-10691 Stockholm, Sweden, \\ email: berndtb@kth.se (B. Björlenius)
}

Received 28 April 2018; Accepted 22 July 2018

\begin{abstract}
A B S T R A C T
The efficiency of five organic and five inorganic sorbents in removing 19 organic micropollutants (MPs), phosphorus, nitrogen, and dissolved organic carbon (DOC) was tested in a two-week column experiment using household wastewater spiked with pharmaceuticals $(n=6)$, biocides/pesticides $(n=4)$, organophosphates $(n=3)$, a fragrance, a UV-stablizer, a food additive, a rubber additive, a plasticizer and a surfactant. Two types of granular activated carbon (GAC), two types of lignite, a pine bark product, and five mineral-based sorbents were tested. All the organic sorbents except pine bark achieved better removal efficiencies of DOC (on average, $70 \pm 27 \%$ ) and MPs $(93 \pm 11 \%$ ) than the inorganic materials (DOC: $44 \pm 7 \%$ and MPs: $66 \pm 38 \%$ ). However, the organic sorbents (i.e. GAC and xyloid lignite) removed less phosphorus $(46 \pm 18 \%)$, while sorbents with a high calcium or iron content (i.e. Polonite ${ }^{\circledR}$ and lignite) generally removed phosphorus more efficiently $(93 \pm 3 \%)$. Ammonium-nitrogen was well removed by sorbents with a $\mathrm{pH}$ between 7 and 9, with an average removal of $87 \%$, whereas lignite ( $\mathrm{pH} 4$ ) showed the lowest removal efficiency $(50 \%)$. Some MPs were well removed by all sorbents ( $\geq 97 \%$ ) including biocides (hexachlorobenzene, triclosan and terbutryn), organophosphates (tributylphosphate, tris-(1,3-dichloro-2-propyl)phosphate and triphenylphosphate) and one fragrance (galaxolide). The pesticide 2,6-dichlorobenzamide and the pharmaceutical diclofenac were poorly removed by the pine bark and inorganic sorbents (on average, $4 \%$ ), while organic sorbents achieved high removal of these chemicals $(87 \%)$.
\end{abstract}

Keywords: Micropollutants (MPs); Synthetic substances; Sorbents; On-site sewage facilities (OSSFs)

*Corresponding author.

1944-3994/1944-3986 @ 2018 The Author(s). Published by Desalination Publications.

This is an Open Access article. Non-commercial re-use, distribution, and reproduction in any medium, provided the original work is properly attributed, cited, and is not altered, transformed, or built upon in any way, is permitted. The moral rights of the named author(s) have been asserted. 